\title{
Excision of a centrally based ventral intradural extramedullary tumor of the cervical spine through a direct posterior approach
}

\author{
Alexander Ghasem ${ }^{1} \cdot$ Joseph P. Gjolaj $^{1}$ - Dylan N. Greif ${ }^{1}$ Barth A. Green ${ }^{2}$
}

Received: 8 June 2017 / Revised: 5 September 2017 / Accepted: 7 September 2017

(C) International Spinal Cord Society 2017

\begin{abstract}
Introduction Intradural extramedullary (IDEM) tumors of the cervical spine are removed through an assortment of surgical approaches including: dorsolateral, ventrolateral, and anterior or transoral. Historically, midline ventral IDEM tumors are ostensibly thought to be unfavorable candidates for removal through a direct posterior approach. A case report of a patient with a ventrally based centrally located meningioma in the upper cervical spine $(\mathrm{C} 2 / \mathrm{C} 3)$ that was removed with direct posterior approach is described.

Case presentation A 51-year-old male presented with cervicalgia and radiating scapular pain following a remote motor vehicle collision. A ventrally located meningioma in relation to the $\mathrm{C} 2$ body was noted on MRI. Management of this patient included obtaining adequate exposure through a posterior approach, complete tumor excision, and maintenance of cervical spine stability. Cervical stability was maintained following total unilateral facetectomy and application of instrumentation from $\mathrm{C} 1-\mathrm{C} 3$.

Discussion Subsequent to tumor removal, the patient had complete resolution of his cervicalgia, headaches, and scapular pain by his two month follow-up appointment. Although adhesions can make total resection difficult, a posterior approach can grant adequate access to midline ventral meningiomas. Cervical spine stability, tumor location, infection risk, and surgeon familiarity with the approach should all be weighed in decision-making.
\end{abstract}

\section{Introduction}

Spinal meningiomas are primarily intradural extramedullary (IDEM) neoplasms that comprise nearly $25 \%$ of all primary spinal tumors [1]. Surgical excision is the mainstay treatment in the majority of cases when patients present with considerable disability. The necessity for surgery and the approach are impacted by multiple factors: tumor size, location relative to spinal cord, anatomical level, neurological status, and comorbidities. Of these, tumor location is thought to contribute most significantly in determining the optimal surgical approach [1]. Given that disease free status after intradural tumor excision is obtainable following

Alexander Ghasem

alexander.ghasem@jhsmiami.org

1 Department of Orthopedic Surgery, University of Miami/Jackson Memorial Hospital, Miami, FL 33131, USA

2 Department of Neurological Surgery, University of Miami/Jackson Memorial Hospital, Miami, FL 33131, USA complete resection, adequate access is important [2]. For ventral cervical meningiomas, several approaches have yielded successful outcomes including anterior/transoral, direct posterior, and dorsolateral/ventrolateral, with each having drawbacks [1, 3-11]. Cervical spine stability, exposure for tumor excision, and risk of post-operative complications must be critically evaluated prior to intervention [12-14].

We present a case of a large ventral centrally located meningioma associated with severe spinal cord compression at the level of $\mathrm{C} 2$ that is surgically resected through a direct posterior approach. This report describes an unusual presentation of an IDEM tumor in an unfavorable location and discusses the unique considerations involved in surgical decision-making.

\section{Case presentation}

A 51-year-old man presented with a 6-month history of severe cervical neck pain and debilitating headaches following a motor vehicle accident. Prior to the accident, he 


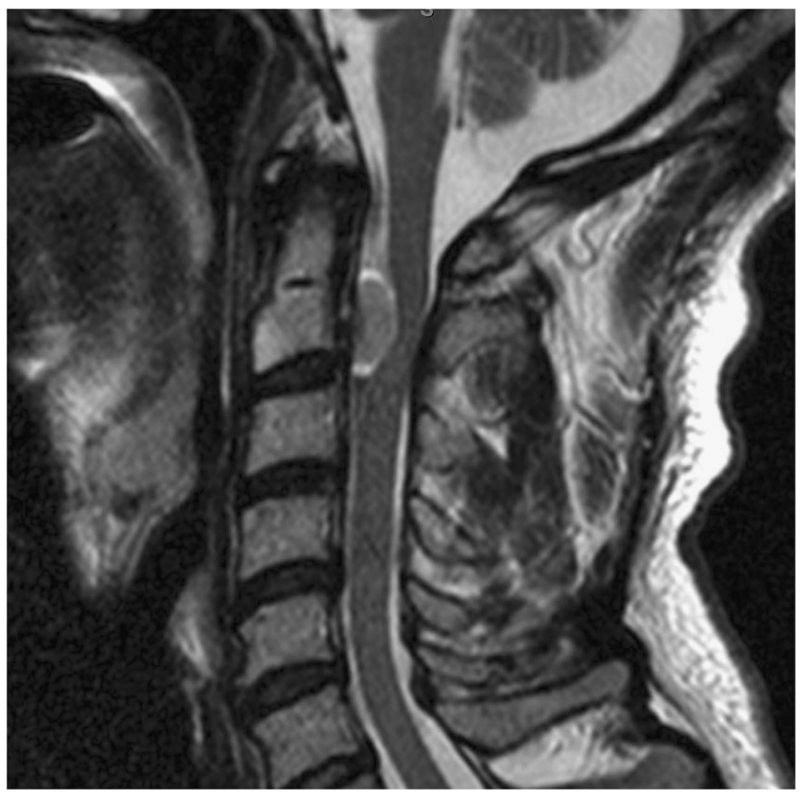

Fig. 1 Sagittal MRI of Intradural Mass Sagittal T2 magnetic resonance imaging of the patient's cervical spine identifying a hypointense intradural extramedullary mass with severe radiographic cord compression

was asymptomatic. He denied gait disturbance, dysesthesias of the extremities, or bowel/bladder symptoms. Conservative management prior to presentation at our institution included physical therapy, warm compresses, and mild oral narcotic pain medication, which yielded minimal relief. Neurological examination revealed no neurological deficits or abnormal reflexes.

Figure 1 shows magnetic resonance imaging (MRI) of the cervical spine notable for a large ventral IDEM mass that is midline at the $\mathrm{C} 2$ level associated with severe cord compression and cord signal change. Homogeneity and hypointensity on both $\mathrm{T} 1$ and $\mathrm{T} 2$ weighted imagings indicated meningioma. The tumor measured $1.7 \times 0.7 \mathrm{~cm}$.

A direct posterior approach was utilized, exposing from $\mathrm{C} 1$ down to $\mathrm{C} 3$ after subperiosteal dissection with deep retractors in place. $\mathrm{C} 1$ lateral mass screws were placed bilaterally after gentle retraction of the $\mathrm{C} 2$ nerve roots with the starting point visualized on lateral fluoroscopic imaging. The lateral mass trajectory was drilled to $22 \mathrm{~mm}$ based on preoperative CT imaging. After tapping and probing to confirm no breach had occurred, lateral mass titanium screws were placed under fluoroscopic visualization. As a result of the operative plan to perform a complete facetectomy on the left side at the level of $\mathrm{C} 2$, no screw was placed at this anatomic site. The right side at the $\mathrm{C} 2$ level and both sides of $\mathrm{C} 3$ were instrumented in the same fashion as the bilateral lateral mass screws performed at $\mathrm{C} 1$.

Prior to application of connecting rods, a left sided complete hemilaminectomy was performed and the pedicle
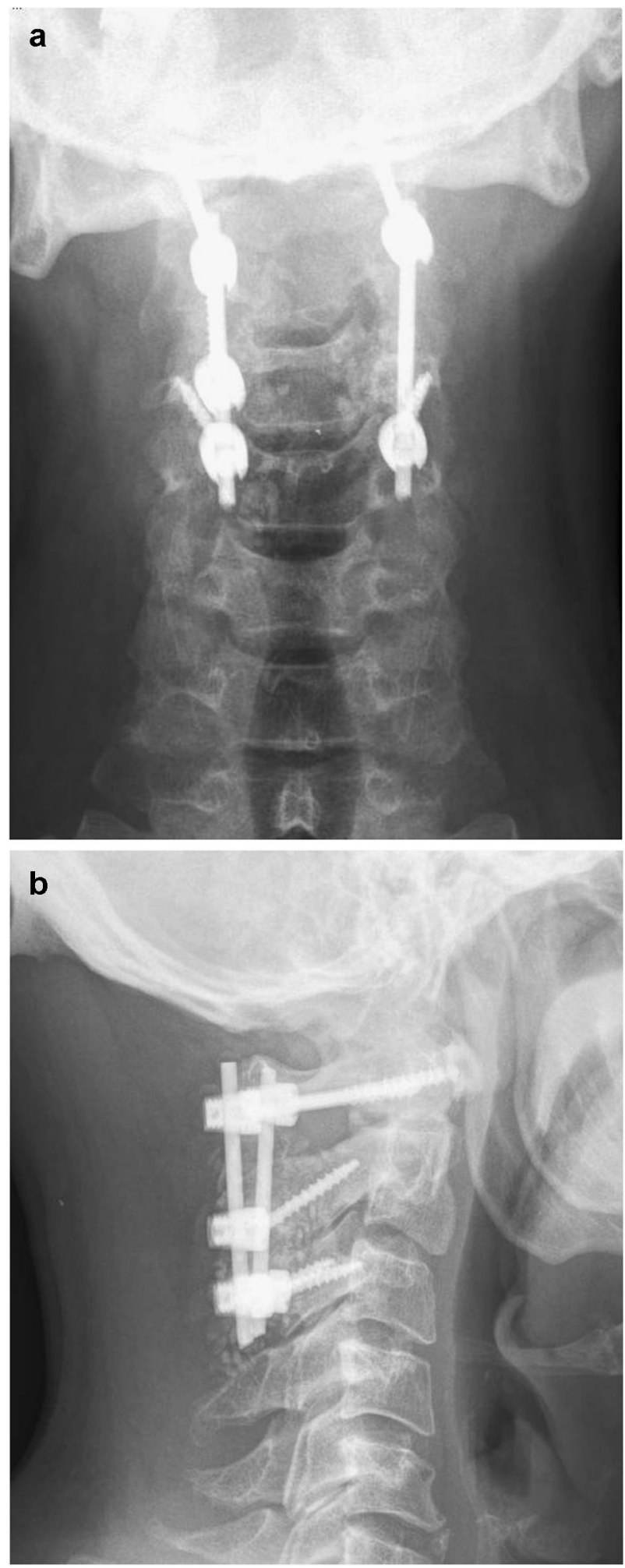

Fig. 2 Postoperative Cervical Radiographs PA (a) and lateral (b) radiographs of the patient's cervical spine following unilateral $\mathrm{C} 2$ facetectomy and partial laminectomy of $\mathrm{C} 1$ and $\mathrm{C} 3$ with implemented cervical instrumentation at levels $\mathrm{C} 1-\mathrm{C} 3$ 
was burred flush to the level of the vertebral body. Partial left side laminectomies were performed at $\mathrm{C} 1$ and $\mathrm{C} 3$ leaving the rostral and caudal portion of the dorsal arch intact at each level, respectively. Using the microscope and micro-instrumentation, a paramedian incision was made in the dura and tacked up with 5-0 prolene suture. Careful dissection was performed with protection of exiting nerve roots abutting the tumor. Biopsies were sent with frozen specimens revealing a diagnosis consistent with meningioma.

Using bipolar with micro-instrumentation as well as adjusting the angulation of the bed and microscope, the tumor was able to be excised. The tumor bed within the dura was then coagulated and overlaid with a graft in areas of dural thinning after meticulous closure of the dura. No cerebral spinal fluid leak was noted upon valsalva. Connecting rods were then contoured and placed followed by decortication and application of bone autograft and allograft to promote posterolateral fusion. Electrophysiologic monitoring was conducted throughout the case and no motor/ sensory changes were noted. The final construct is visualized in Fig. 2a, b.

Postoperatively, the patient's cervicalgia and severe headaches resolved and his neurological exam remained normal. At the 4 month follow-up visit, the patient noted resolution of his headaches. He discontinued the usage of narcotics and had occasional spasms that were relieved with low frequency flexeril. His last follow-up MRI for this visit showed mild scaring with no frank recurrence along the construct stable as well as no change in positioning of the instrumentation. The patient was satisfied with his results.

\section{Statement of ethics}

We certify that all applicable institutional and governmental regulations concerning the ethical use of human volunteers were followed during the course of this research.

\section{Discussion}

Given the slow growth rate and nonmalignant characteristics, spinal meningiomas respond well to complete surgical excision, as in this case [15-21]. Precautions to avoid recurrence are important since revision surgery has proven substantially more challenging once the native arachnoid plane is disrupted by primary surgery [4, 22]. Cohen-Gadol et al.'s findings suggest that patients over age 50 have a $5 \%$ recurrence rate following tumor removal [22, 23]. Ensuring sufficient tumor removal is dependent upon surgical approach and adequate exposure. This is particularly true in the case of ventral intradural neoplasms.
Classically, posterior approaches have been regarded as unsuitable for centrally located ventral tumors. However, based on our institutional experience, we elected to employ a posterior approach. Kim et al. [2] performed a conventional posterior approach involving a single-sided laminectomy and partial facetectomy, based upon the laterality of the tumor, to resect 18 ventral intradural tumors. Complete surgical excision was achieved in 17 of 18 of these tumors with no reports of cervical instability. In our case, a complete facetectomy and adjacent level partial laminectomies were performed. This allowed for the meningioma to be excised using standard microsurgical techniques with minimal spinal cord manipulation, resulting in no neurological deficits. While performing a total facetectomy afforded improved exposure, it compromised cervical stability and necessitated instrumented fusion. Similarly, an anterior/ transoral approach at $\mathrm{C} 2$ would have led to inherent cervical instability and the need for instrumentation. We opted against the transoral approach given the rate of posterior pharyngeal wall dehiscence and postoperative infection nearing $6 \%$ in cervical tumors, according to Shousa et al. [24].

Surgical management of ventrally based cervical IDEM tumors is formidable and their excision can be problematic. These centrally based ventral tumors may successfully be excised using a posterior approach, but cervical stability and risk of neurological dysfunction should be considered.

\section{Compliance with ethical standards}

Conflict of interest Each author certifies that he or she has no commercial associations (e.g., consultancies, stock ownership, equity interest, patent/licensing arrangements, etc.) that might pose a conflict of interest in connection with the submitted article. No copyrighted information was presented in this case report.

\section{References}

1. Slin'ko EI, Al Q II. Intradural ventral and ventrolateral tumors of the spinal cord: surgical treatment and results. Neurosurg Focus. 2004; 17:ECP2.

2. Kim $\mathrm{CH}$, Chung CK. Surgical outcome of a posterior approach for large ventral intradural extramedullary spinal cord tumors. Spine. 2011;36:E531-37.

3. Conti P, Pansini G, Mouchaty H, Capuano C, Conti R. Spinal neurinomas: retro-spective analysis and long-term outcome of 179 consecutively operated cases and review of the literature. Surg Neurol. 2004;61:34-43.

4. Klekamp J, Samii M. Surgical results for spinal meningiomas. Surg Neurol. 1999;52:552-62.

5. Arnautovi KI, Al-Mefty O, Husain M. Ventral foramen magnum meningiomas. J Neurosurg. 2000;92:71-80.

6. Bassiouni H, Ntoukas V, Asgari S, Sandalciouglu EL, Stolke D, Seifert V. Foramen magnum meningiomas: clinical outcome after microsurgical resection via a posterolateral suboccipital retrocondylar approach. Neurosurgery. 2006;59:1177-85. 
7. Boström A, Bürgel U, Reinacher P, Krings T, Rohde V, Gilsbach $\mathrm{JM}$, et al. A less invasive surgical concept for the resection of spinal meningiomas. Acta Neurochir (Wien). 2008;150:551-6.

8. Schaller B. Spinal meningioma: relationship between histological subtypes and surgical outcome? J Neurooncol. 2005;75: $157-61$.

9. Setzer M, Vatter H, Marquardt G, Seifert V, Vrionis FD. Management of spinal meningiomas: surgical results and a review of the literature. Neurosurg Focus. 2007;23:E14.

10. Steck JC, Dietze DD, Fessler RG. Posterolateral approach to intradural extramedullary thoracic tumors. J Neurosurg. 1994;81:202-5.

11. Beall DP, Googe DJ, Emery RL, Thompson DB, Campbell SE, Ly JQ, et al. Extramedullary intradural spinal tumors: a pictorial review. Curr Probl Diagn Radiol. 2007;36:185-98.

12. Albanese V, Platania N. Spinal intradural extramedullary tumors. Personal experience. J Neurosurg Sci. 2002;46:18-24.

13. Banczerowski P, Lipóth L, Vajda J, Veres R. Surgery of ventral intradural midline cervical spinal pathologies via anterior cervical approach: our experience. Ideggyogy Sz. 2003;56:115-8.

14. Aboul-Enein HA, Khidr WM, Abdeen KM, Madawi AA. Surgical management of ventrally based lower cervical (subaxial) meningiomas through the lateral approach: Report on 16 cases. Clin Neurol Neurosurg. 2015;139:152-8.

15. Arima H, Takami T, Yamagata T, Naito K, Abe J, Shimokawa N, et al. Surgical management of spinal meningiomas: A retrospective case analysis based on preoperative surgical grade. Surg Neurol Int. 2014;5(Suppl 7):S333-8.
16. Cohen-Gadol AA, Zikel OM, Koch CA, Scheithauer BW, Krauss WE. Spinal meningiomas in patients younger than 50 years of age: A 21-year experience. J Neurosurg. 2003;98:258-63.

17. Gezen F, Kahraman S, Canakci Z, Bedük A. Review of 36 cases of spinal cord meningioma. Spine (Phila Pa 1976). 2000;25:727-31.

18. Gottfried ON, Gluf W, Quinones-Hinojosa A, Kan P, Schmidt MH. Spinal meningiomas: Surgical management and outcome. Neurosurg Focus. 2003;14:e2.

19. Hong-Wan N, Ee-Chon T, Qing-Hang Z. Biomechanical effects of C2-C7 intersegmentalstability due to laminectomy with unilateral and bilateral facetectomy. Spine (Phila $\mathrm{Pa}$ 1976). 2004;29:1737-46.

20. Voo LM, Kumaresan S, Yoganandan N, Pintar FA, Cusick JF. Finite element analysis of cervical facetectomy. Spine (Phila Pa 1976). 1997;22:964-9.

21. William AS, Jonathan AB. Principles of spinal surgery. Lateral approachs to the cervical spine. Vol. 2, Mcgraw-Hill Companies Inc, New York, 1996.

22. Takami T, Naito K, Yamagata T, Yoshimura M, Arima H, Ohata K. Posterolateral approach for spinal intradural meningioma with ventral attachment. J Craniovertebr Junction Spine. 2015;6:173-8.

23. Cohen-Gadol AA, Zikel OM, Koch CA, Scheithauer BW, Krauss WE. Spinal meningiomas in patients younger than 50 years of age: A 21-year experience. J Neurosurg. 2003;98(Suppl 3):258-63.

24. Shousha M, Mosafer A, Boehm H. Infection rate after transoral approach for the upper cervicalspine. Spine. 2014;39:1578-83. 